\title{
Status Survey on Art Therapy in Special Education Schools
}

\author{
Mei Zhang \\ College of the Special Education \\ Leshan Normal University \\ Leshan, China 614000
}

\begin{abstract}
In this survey, the author, mainly adopting the questionnaire method and the interview method, investigates the current situation of the implementation of art therapy in $\mathbf{1 6}$ special education schools in Sichuan province. The survey results show that there is a disproportion between male teachers and female teachers and they are generally young with short years of teaching; these schools have too many part-time teachers, lacking professional teachers and high-end talents, and the degree of involvement of parents and students is low. Based on the survey, the author puts forwards a development strategy that we shall enhance the quality therapy by improving the professional level and quality of the art therapy teachers in Sichuan special education schools to provide more high-quality art therapy methods to the students, thus making the art therapy in Sichuan special education schools take on a new look.
\end{abstract}

Keywords-Sichuan; special education schools; art therapy; status survey

\section{INTRODUCTION}

Art therapy is a psychological therapy method, which originated in the two different fields of art and psychotherapy and uses art as the medium to achieve the "therapy" purpose. The major characteristic of art therapy is that it is rich in methods of expression. Art therapy, as a kind of psychological therapy, has a variety of forms and is carried out centering on art activities, including music therapy, painting therapy, pottery therapy, dance therapy, drama therapy, art modeling therapy, poetry therapy, visual arts therapy, cultural therapy, reading therapy and so on. Such kinds of therapy creates a free, easy, safe and open atmosphere for patients to reduce their psychological defense and make them relax themselves. They have a common that they use nonverbal communication forms to help visitors with self-expression, reflection and externalization of pent-up feelings and dealing with emotional distress to realize the purpose of therapy. Luo Lan [1] believes that art therapy can provide tailored rehabilitation training for autistic children in inclusive education to help them become a part of the group as soon as possible, deal with emotional problems and significantly improve the ability of selfawareness and integration with team, so it can promote the cognition, language expression ability, communication skills and other abilities of autistic children. According to characteristics of physical and mental development and needs of children with special needs, the comprehensive art education and therapy (including music, painting, drama, dance and other forms), which crosses over psychological therapy, special education, education rehabilitation and other fields, can tap the artistic ability of children with special needs through rich and diverse art education training and rehabilitation activities, including appreciation, children's songs, singing, rhythm, dance, painting, picture books, instrument playing, improvisation, plastic arts, drama and other specific forms, so as to promote their abilities of language, cognition, emotion, action and social adaptation, harmonious development of body and mind, as well as their personality and life quality. Hou Qingqi [2] gave art therapy for 15 students with hearing impairment once a week for 90 minutes, 8 times in total. The results showed that art therapy can significantly improve the mental health, self-esteem together with self consistency and congruence of students with hearing impairment. In the process of intervention, the art therapy gradually enhanced the ability of students with hearing impairment to communicate with others, strengthened their self-confidence and resilience, and thus improving their sense of self-efficacy. Hao Zhenjun and Cao Yanying [3] provided early intervention for 10 first-grade students with mental retardation via painting therapy. The results showed that painting therapy could effectively improve the observation ability, intuitive thinking ability, language expression ability, memory, imagination and other relevant abilities of most children with mental retardation. Zhang Wen [4] designed a painting therapy intervention scheme and provided the painting therapy for 60 autistic children, aiming to realize the combination of individuals and the group. The results showed that the painting therapy can give the autistic children sensory stimuli and pacify their emotions at the same time; group activities can also promote the interaction among autistic children, develop their interpersonal skills, and contribute to the formation and development of healthy personality and psychological quality. Chen Kun [5], by adopting the case method, provided painting therapy for two children with aggressive behavior. The results showed that with the aggressive behavior of different children may be caused by different deep reasons; painting can help the children express their different inner conflicts and contradictions so that we can find out the deep cause and targetedly help them. In addition, painting therapy can adjust the children's chaotic mind into a clear and orderly state, promote the development of their cognition and emotion, and reduce their aggressive behaviors. Through questionnaire survey and field investigation, this paper learns about the current situation of the implementation 
of art therapy in special education schools in Sichuan, and put forward constructive suggestions accordingly.

\section{RESEARCH OBJECT AND METHOD}

\section{A. Research Object}

This study selects 16 special education schools in Sichuan province to investigate the status of implementation of art therapy there.

\section{B. Research Method}

1) Literature review method: This paper collected and sorted out the literature of art therapy research at home and abroad to obtain a comprehensive understanding of the connotation, classification, intervention mode and effect of the art therapy.

2) Questionnaire method: After consulting relevant literature, the author prepared a questionnaire to investigate the current situation of art therapy in Sichuan special education schools, which covers four dimensions, including teachers, students, parents and schools. Among the 16 special education schools in Sichuan province, 54 teachers engaged in art therapy teaching were selected for the questionnaire survey. 54 copies of the questionnaire were issued and 54 copies were recovered, with the recovery rate of $100 \%$ and the effective rate of $100 \%$.

3) Interview method: In this paper, the author compiled interview outlines as the supplement of the questionnaire survey. By interviewing 16 leaders and some teachers of the 16 special education schools, the author obtained some information about objective situation of art therapy in the special education schools and subjective opinions and plans of the leaders and teachers of special education schools on the art therapy of their schools to provide more realistic basis for putting forward feasible strategies in the paper.

4) Mathematical statistics: This paper adopts Excel2010 for statistic analysis of relevant data obtained from questionnaires and interviews.

\section{RESULTS AND ANALYSIS}

\section{A. Survey Results and Analysis of Art Therapy Teachers in Sichuan Special Education Schools}

1) Survey results and analysis of basic information of the art therapy teachers

\begin{tabular}{|c|c|c|c|c|c|c|c|}
\hline & & $\begin{array}{c}\text { Under 20 } \\
\text { Years Old }\end{array}$ & $\begin{array}{l}\text { 20-30 Years } \\
\text { Old }\end{array}$ & $\begin{array}{l}\text { 30-40 Years } \\
\text { Old }\end{array}$ & $\begin{array}{c}\text { 40-50 Years } \\
\text { Old }\end{array}$ & $\begin{array}{c}\text { Above } 50 \text { Years } \\
\text { Old }\end{array}$ & Total \\
\hline \multirow[t]{2}{*}{ Sex } & Male & $0(0 \%)$ & $2(3.7 \%)$ & $3(5.6 \%)$ & $1(1.9 \%)$ & $0(0 \%)$ & $6(11.1 \%)$ \\
\hline & Female & $2(3.7 \%)$ & $34(60.7 \%)$ & $7(12.5 \%)$ & $3(5.6 \%)$ & $2(3.7 \%)$ & $48(88.9 \%)$ \\
\hline \multirow{2}{*}{$\begin{array}{l}\text { Full-time } \\
\text { or } \\
\text { part-time }\end{array}$} & Full-time & $1(1.9 \%)$ & $22(40.7 \%)$ & $5(9.3 \%)$ & $1(1.9 \%)$ & $0(0 \%)$ & $29(53.7 \%)$ \\
\hline & Part-time & $1(1.9 \%)$ & $14(25.9 \%)$ & $5(9.3 \%)$ & $3(5.6 \%)$ & $2(3.7 \%)$ & $25(46.3 \%)$ \\
\hline
\end{tabular}

We can see from "Table I" that female teachers aged from 20 to 30 in art therapy are the most, accounting for $60.7 \%$; art therapy teachers are mainly young and middle-aged; and parttime teachers account for $46.3 \%$. They are the main force of art therapy teachers at present. As special education in Sichuan province starts to develop rapidly only in recent years, many special education schools did not know about art therapy before, and most of the existing art therapy teachers are newly recruited. However, young teachers have good physical quality and can do high-intensity work for a relatively long time, and at the same time, they have high enthusiasm and positivity for work, active mind and novel ideas, which are of positive significance for the innovation and development of art therapy.

Among the 54 art therapy teachers the author investigated in special education schools, there are 48 female teachers, accounting for $89 \%$, and only 6 male teachers, accounting for only $11 \%$ of the total. The ratio of female to male teachers is 8 to 1 , and the proportion of part-time teachers is high. Art therapy is still a new course in the field of special education in China, and the teachers engaged in art therapy are seriously inadequate. Therefore, Sichuan special education schools that did not recruit professional art therapy teachers, have to select teachers of other subjects to concurrently serve as art therapy teachers; in addition, some special education schools do not pay much attention to art therapy, but set up simple courses of art therapy as a response to national policies, instead of implementing substantive art therapy.

2) Survey results and analysis on years of teaching, education background and majors of art therapy teachers: According to "Table II" art therapy teachers in Sichuan special education schools are characterized by short years of teaching, among which those with less 10 years of teaching account for $81.5 \%$. It is doubtless that art therapy teachers with short years of teaching have less teaching experience, inadequate teaching ability and less control of the classroom, which requires Sichuan special education schools to provide more high-quality teaching training for the art therapy teachers. We can also see from "Table II" that most of the teachers engaged in art therapy are undergraduates, accounting for $63.0 \%$. The undergraduates who received higher education are obviously better than those with lower education background in teaching idea, innovation, learning of new things and other aspects, so the teachers' constitution dominated by undergraduates has a certain positive significance for special education schools in teaching innovation, integration of new concepts, application of 
multiple modern teaching means, etc. In addition, "Table II" also shows that among art therapy teachers in Sichuan special education schools, teachers that majored in fine arts account $53.7 \%$ and are the main force of the art therapy teachers.
However, art therapy teachers who majored in fine arts are still required to further improve their professional theory and knowledge in art therapy.

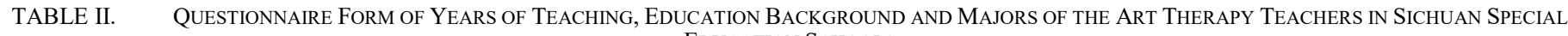
EDUCATION SCHOOLS

\begin{tabular}{llll}
\hline & & n & \% \\
\hline Years & Less than 5 years & 15 & 27.8 \\
of teaching & 5-10 years & 29 & 53.7 \\
& 10-15 years & 8 & 14.8 \\
& 15-20 years & 2 & 3.7 \\
& More than 20 years & 0 & 0 \\
Education & Secondary normal school and technical secondary school & 5 & 9.3 \\
background & Junior high school & 2 & 3.7 \\
& Senior high school & 5 & 9.3 \\
& Junior college & 8 & 14.8 \\
& Bachelor & 34 & 63.0 \\
& Degree above bachelor & 0 & 0 \\
& Fine arts & 29 & 53.7 \\
& Special education & 13 & 24.1 \\
& Education other than fine arts and special education & 9 & 16.7 \\
& Others & 3 & 5.6 \\
\hline
\end{tabular}

\section{B. Survey and Analysis on the Implementation of Art Therapy} in Sichuan Special Education Schools

At present, the teaching contents of art therapy in Sichuan special education schools is mostly arranged by teachers themselves, which is generally casual and scattered. There is no uniform textbook, neither school-based textbook.

TABLE III. SOURCE OF TEACHING CONTENT OF ART THERAPy TEACHERS IN SiCHuAN SPECIAL EdUCATION SCHOOLS (\%)

\begin{tabular}{ccccccc}
\hline & $\begin{array}{c}\text { Life } \\
\text { Materials }\end{array}$ & $\begin{array}{c}\text { Purchased } \\
\text { Textbook }\end{array}$ & $\begin{array}{c}\text { Network } \\
\text { Resource }\end{array}$ & $\begin{array}{c}\text { Students' } \\
\text { Interests }\end{array}$ & $\begin{array}{c}\text { School-based } \\
\text { Teaching Textbook }\end{array}$ & $\begin{array}{c}\text { Others } \\
\text { Reacher }\end{array}$ \\
\hline Proportion & 72.2 & 42.6 & 75.9 & 59.3 & 0 & 3.7 \\
\hline
\end{tabular}

According to "Table III", it can be concluded that the current teaching content of art therapy teachers in Sichuan special education schools mainly comes from network resource, life materials, students' interests and purchased textbooks, and no teachers use school-based textbooks at present. There are many and miscellaneous channels for teachers to obtain teaching content, and no unified standards and regulations, so teachers are relatively free and aimless in choosing teaching content. Many part-time art therapy teachers lack certain identification ability and will include some teaching contents that are not suitable for special students. As a result, they cannot establish a relatively systematic art therapy teaching and the teaching is also varying in quality.

Sichuan, as a province with a long history and rich culture, retains many precious traditional arts and crafts, such as Sichuan embroidery in Chengdu, tie-dye in Emei, manual papermaking in Jiajiang County, water-diversion oiled paper umbrella in Luzhou, bamboo weaving handcraft in Daoming, Chongzhou, bamboo carving technology in Jiangan and paper cutting in Zigong. Many traditional arts and crafts are an important part of the intangible cultural heritage and the treasure for the land of Bashu. Adding traditional arts and crafts into teaching can not only improve the characteristics and originality of art therapy, but also have important significance for protecting these cultural heritages. Education Rehabilitation Center of Wuxi Binhu District has started to apply local earthen figures peculiar to Huishan in art therapy teaching of mentally retarded students; Urumqi School for the Deaf also introduced local hereditary handcraft - traditional earthware jar to the fine arts classroom and made innovation to produce paper artistic jars by using waste materials [6]. Lin Hongjie [7] also pointed out that introducing the traditional "three carvings and one sculpture" and other folk arts and crafts of Zhejiang into the vocational education for deaf students not only conforms to deaf students' psychological characteristics-- hard-working and careful in doing things, but also is conducive to the inheritance and development of traditional handicrafts of Zhejiang province.

At present, art therapy in Sichuan special education schools is mainly given in the form of painting class and handcraft class, separately, and there is barely class combination of handwork and painting. The teaching content of handcraft class mainly includes paper art, clay art, cloth art, crafts, vocational skills and waste renovation. The teaching content of painting class mainly includes painting, traditional Chinese painting, sketch, oil painting, crayon painting, creative painting, watercolor painting, gouache, animation design, etc. 
C. Survey Results and Analysis on the Involvement of Students and Parents in Art Therapy in Sichuan Special Education Schools

TABLE IV. Questionnaire Form of Teachers’ Perception of Students’ Interests IN Classes (\%)

\begin{tabular}{lcccc}
\hline $\begin{array}{c}\text { Teachers' } \\
\text { Perception }\end{array}$ & $\begin{array}{c}\text { Almost All Students Are } \\
\text { Interested In }\end{array}$ & $\begin{array}{c}\text { Most Students Are } \\
\text { Interested In }\end{array}$ & $\begin{array}{c}\text { Only A Minority of } \\
\text { Students Are Interested } \\
\text { in }\end{array}$ & $\begin{array}{c}\text { Almost No Students Are } \\
\text { Interested In }\end{array}$ \\
\hline $\begin{array}{l}\text { Deaf students } \\
\text { Mentally retarded }\end{array}$ & 7.4 & 77.8 & 14.8 & 0 \\
students & 31.5 & 64.8 & 3.7 & 0 \\
\hline
\end{tabular}

It can be seen from "Table IV" that $77.8 \%$ of art therapy teachers believe that most deaf students are interested in art therapy; $31.5 \%$ of art therapy teachers believe that almost all mentally retarded students are interested in art therapy. This shows that at present most students are interested in art therapy in Sichuan special education schools; and mentally retarded students are more interested in art therapy than deaf students.

TABLE V. ART THERAPY TEACHERS`EVALUATION OF EFFECTS OF ART THERAPY FOR STUdENTS IN SiCHUAN SPECIAL EDUCATION SCHOOLS (\%)

\begin{tabular}{lcccc}
\hline \multicolumn{1}{c}{ Teacher Evaluation } & Very Good & Relatively Good & Not Satisfactory & Very Bad \\
\hline Deaf students & 14.8 & 75.9 & 7.4 & 1.9 \\
Mentally retarded students & 5.6 & 25.9 & 59.3 & 9.3 \\
\hline
\end{tabular}

From "Table V", we can see that $75.9 \%$ of teachers think that art therapy teaching for deaf students achieves satisfactory result, while $59.3 \%$ of teachers think that learning effect of mentally retarded students is not ideal. This result is related to the cognitive characteristics of the students with two different disorder types, and requires teachers to carry out targeted and practical teaching in art therapy according to the characteristics of students with different disorder types.

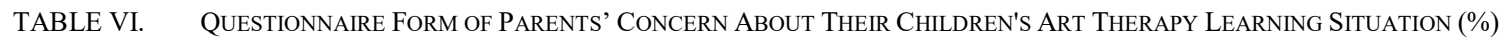

\begin{tabular}{lcccc}
\hline & $\begin{array}{c}\text { Almost All Parents } \\
\text { Will Do So }\end{array}$ & $\begin{array}{c}\text { Most Parents } \\
\text { Will Do So }\end{array}$ & $\begin{array}{c}\text { Only A Minority of } \\
\text { Parents Will Do So }\end{array}$ & $\begin{array}{c}\text { Almost No Parents } \\
\text { Will Do So }\end{array}$ \\
\hline $\begin{array}{l}\text { Deaf students } \\
\text { Mentally retarded } \\
\text { students }\end{array}$ & 3.7 & 31.5 & 57.4 & 7.4 \\
\hline
\end{tabular}

Parents play a very important role in the study and life of special students. In the art therapy, parents' support and concern for the special children have a great influence on the effect of art therapy teaching. It can be seen from "Table VI" that $31.5 \%$ of art therapy teachers believe that most parents of deaf students care about the effect of art therapy on their children; $42.6 \%$ of art therapy teachers believed that only a few parents of mentally retarded students will take the initiative to care about their children's art therapy learning. This also reflects that parents of deaf students need to improve their concern for their children's art therapy effect, while parents of mentally retarded students care so little about their children's learning condition and are required to attach more importance to their children's art therapy.

\section{CONCLUSION}

\section{A. Establishing Art Therapy Courses with Applicability and Practicability}

At present, one of the major characteristic of art therapy in Sichuan special education schools is that it is not close to life and students cannot acquire practical knowledge from class. Special children, especially those mentally retarded ones, due to their own cognitive characteristics, have limited ability to accept knowledge and are different from normal children in the angle of needs of knowledge. Their education should focus on their social adaptation and self-care ability. As with life adaptation class, art therapy should develop towards daily life and practicality. Scientific research reveals that more than 80 percent of people's learning experience is obtained through vision [8]. Art therapy is a discipline that can provide a strong visual stimuli and introducing life experience teaching in the teaching of art therapy is not only beneficial to special children to develop their independent living ability and social adaptability, but also can facilitate special children to understand the teaching content, so that the art therapy can be repeated in the theory and practice continuously thus to strengthen the teaching effect.

\section{B. Highlighting Fine Arts Therapy Course}

Art therapy proposed and established in 1930s is a service occupation that presents individual development, ability, personality, interest, attention and conflict through painting medium or material, artistic creation images, creative art activities and patients' feedback on works [9]. In the development process of fine arts therapy, it has been proved that art therapy has a significant effect on special children, mainly reflected in the following aspects: developing hand operation skills of special children and their fine movements; promoting special children's emotion expression and 
acquisition of self-awareness; developing the social communication ability of special children. Sichuan special education schools may adopt fine arts therapy-based methods to provide individualized art therapy for different special children and establish high-efficiency art therapy class with both therapy and education functions.

\section{Improving Teaching Faculty}

Teachers lead the teaching activities and are the key to art therapy reform in Sichuan special education schools. At present, there is a disproportion between male teachers and female teachers in art therapy of Sichuan special education schools, and these teachers are generally young with short years of teaching; these schools have too many part-time teachers, lacking professional teachers and high-end talents. Based on these facts, in terms of teaching faculty building, these schools should provide professional training to improve the professionalization of art therapy teachers; introduce highend talents to improve the academic level of art therapy teachers; in addition, these teachers should also attach importance to improving their teaching quality and professional skills and broadening their scope of knowledge through active learning, overcome sluggishness and improve enthusiasm in work.

\section{REFERENCES}

[1] Luo Lan. Analysis of Adjustment Path of Art Therapy in Treatment of Autistic Children [J]. The Guide of Science \& Education- Electronic Edition (Midmonth), 2016 (12):126. (in Chinese)

[2] Hou Qingqi. Research on Strategies of Constructing Positive Psychological Field for College Students with Hearing Impairment from the Perspective of Art Therapy [J]. Journal of Huaibei Normal University (Philosophy and Social Sciences (Philosophy and Social Science Edition), 2017 (6):120-125. (in Chinese)

[3] Hao Zhenjun, Cao Yanying. A Preliminary Study on Art Therapy with Mental Retardation in Lower Grades [J]. Chinese Journal of Special Education, 2004 (5):27-30. (in Chinese)

[4] Zhang Wen. Survey on Multiple Factors of Autistic Children and Painting Art Therapy Intervention[D]. Shanxi Medical University, 2009. (in Chinese)

[5] Chen Kun, Bian Xia. On the Application of the Drawing Projection Technology in Aggressive Children's Psychology Analysis [J]. Studies In Preschool Education, 2010 (12):15-20. (in Chinese)

[6] Xu Shijie. Wonderful Handwork of Deaf Students - Reproduction and Exploration of Earthware Jar Made in Urumqi School for the Deaf by Using Scrap Materials[J]. Education \& Teaching Forum, 2012, 39:187188. (in Chinese)

[7] Lin Hongjie. Vocational Education for the Deaf and Inheritance of Folk Handicraft [J]. Disability in China, 2013 (2):57. (in Chinese)

[8] Wang Shiyun. Practical Exploration of Art Therapy Adaptation Teaching in School for the Mentally Retarded [D]. Henan Normal University, 2015. (in Chinese)

[9] Sun Xia. Art Therapy for Special Children [M]. Peking University Press, 2011. (in Chinese) 